\title{
Comparative Evaluation of Push-Out Bond Strength of Three Bioactive Retrograde Filling Materials using Different Retro-Preparation Techniques (An in Vitro Study)
}

\author{
Maha A. Habeeb ${ }^{1}$, Haitham D. Muhsen², Zainab M. Kamel ${ }^{3}$, Samer A. Thiab ${ }^{4}$, Athil A. Al-Kinani ${ }^{5}$ \\ ${ }^{1,3,4}$ Restorative and Aesthetic Department, College of Dentistry, University of Baghdad \\ ${ }^{2}$ Restorative and Aesthetic Department, College of Dentistry, AlMostansriya University \\ ${ }^{5}$ Ministry of Health, AlKrama dental specialist center
}

\begin{abstract}
Background: The aim of this study was to evaluate and compare the push-out bond strength around retrograde cavities prepared with ultrasonic technique and conventional method and filled by three types of retrograde bioceramic materials. Materials and methods: 30 extracted single rooted human permanent maxillary teeth with mature apices were selected. The roots were prepared chemo-mechanically using protaper files (Dentsply Maillefer, Ballaigues, Switzerland) (SX to F5) with crown-down technique and then obturated with lateral condensation gutta-percha technique. The roots were sectioned transversally at two points: $3 \mathrm{~mm}$ short of the apical foramen with straight fissure bur (which is the level of apicoectomy) and $4 \mathrm{~mm}$ coronally to this point to obtain an apical root section or slice of $(4 \mathrm{~mm})$ high. A total of 30 apical root slices were divided into three main groups according to the type of retrograde filling: Group A (Biodentine group) (n=10): which were subdivided into: $A 1$ ( $n=5):$ in which a class I retro cavity were prepared using Piezoelectric ultrasonic device equipped with ultrasonic surgical retro tip (surgysonic I, ESO3A) at (30-kHz) frequency and A2 (n=5): In which class I retro cavity were prepared with right-angled low speed Handpiece (W\&H, Austria) equipped with carbide round bur \#2 (Komet Dental, Austria). After that retrograde cavities were filled with Biodentine (Septodent, France) Group B (MTA group) (n=10): which were subdivided into: $B 1(n=5)$ : in which a class I retro cavity were prepared using Piezoelectric ultrasonic device equipped with ultrasonic surgical retro tip (surgysonic I, ESO3A) at (30-kHz) frequency and B2 (n=5): In which class I retro cavity were prepared with right-angled low speed Handpiece (W\&H, Austria) equipped with carbide round bur \#2 (Komet Dental, Austria). After that retrograde cavities were filled with MTA (ProRoot MTA, Dentsply). Group C (TheraCal LC group) (n=10): which were subdivided into: C1 (n=5): in which a class I retro cavity were prepared using Piezoelectric ultrasonic device equipped with ultrasonic surgical retro tip (surgysonic I, ESO3A) at (30-kHz) frequency and $C 2(n=5):$ In which class I retro cavity were prepared with right-angled low speed Handpiece (W\&H, Austria) equipped with carbide round bur \#2 (Komet Dental, Austria). After that retrograde cavities were filled with TheraCal LC(Bisco, Inc.). Then all the specimens were kept in wet gauze of normal saline for 2 day. The specimens were then fixed in an Instron universal testing machine (Instron Corp., Canton, MA, USA). Maximum load applied to material at the time of dislodgement were recorded in Newton's and data were recorded using computer software, then bond strength was calculated from the recorded peak by special formula and the slices were then examined under a light microscope at 20x magnification to determine the nature of the bond failure. Results: Statistical analysis showed a highly significant difference in push-out bond strength among the tested groups in which Biodentine has proved superiority in dislodgment resistance when compared to MTA and TheraCal. Also push-out bond strength was significantly higher with ultrasonic prepared cavities when compared with conventional method for Biodentin group and non significant difference for MTA and TheraCal groups between ultrasonic and conventional method. We observed mostly adhesive failures in MTA groups, while TheraCal showed predominance of mixed failures. Almost all Biodentine samples revealed a cohesive bond failure. Conclusion: 1. The force needed for the dislodgement of Biodentine from root dentin was statistically highly significant when compared to MTA and TheraCal. 2- Statistically significant differences were found comparing the results of ultrasonic retrotip preparation versus conventional bur preparation in which ultrasonics produced significantly better push-out bond strength for Biodentin group and non significant difference for MTA and TheraCal groups between ultrasonic and conventional method.
\end{abstract}

Keywords: push-out bond strength, Bioceramic filling materials, Piezoelectric ultrasonic device, retrograde cavities

\section{Introduction}

When conventional root canal treatment fails, apical surgery is recommended. This procedure requires the root-end resection, eliminating the contaminated portion of the root where the microorganisms are resistant to the disinfection of the canal and placement of retrograde filling [1].

Selection of a root-end filling material that has adequate physicochemical properties and fulfills the criteria of biocompatibility, cytotoxicity, apical seal and marginal adaptation is of utmost importance for a good clinical prognosis. Root-end filling materials should seal the contents of root canal system to prevent the egress of microorganisms or their byproducts into periradicular tissues [2]. Among the physicochemical properties, adhesiveness to intraradicular dentin is of particular interest because root-end filling materials must be able to remain adapted to the dentin walls when the teeth are subjected to mechanical forces occurring during function or operative and surgical procedures[3]. However, there is not a specific methodology for evaluating the bond strength of root-end filling materials and, for this reason, the same specimen preparation protocol and testing standards originally designed for root canal sealers through push-out test have been employed in retrofilling research as well [4].

Volume 6 Issue 7, July 2017 


\section{International Journal of Science and Research (IJSR) \\ ISSN (Online): 2319-7064}

Index Copernicus Value (2015): 78.96 | Impact Factor (2015): 6.391

Push-out bond test has been shown to be reliable and it has been successfully used for measuring the dislocation resistance and the bond strength of a restorative material to dentin. This test is an effective, dependable, and feasible method to evaluate the stability of an endodontic material in its surrounding root canal dentin [5].

The terms bioactive material is defined as a material that has the effect on or eliciting a response from living tissue, organisms or cell such as inducing the formation of hydroxyapatite. The ideal properties of bioactive material are; bactericidal and bacteriostatic, sterile, stimulate reparative dentine formation and maintain pulp vitality [6]. An example of such material is Mineral trioxide aggregate (ProRoot MTA, Dentsply) which has been used for repair of root perforations, root end filling material, vital pulp therapy and as an apical barrier for teeth with open apices making it an extremely popular endodontic material [7]. Two new cements have been presented with the aim of enhancing some of the MTA shortcomings. The first cement is Biodentine (Septodont, Saint-Maur-des-Fosses, France) which is a bioactive dentin replacement material having similar properties of dentin and has a positive effect on vital pulp cells stimulating tertiary dentin formation and composed of tricalcium silicate, calcium carbonate, zirconium oxide, and a water-based liquid containing calcium chloride used as setting accelerator and waterreducing agent [8]. The second cement is TheraCal LC (Bisco, Inc.) which is a light-cured resin-modified calcium silicate-filled base/liner material used for pulp capping. It shows physiochemical bonding to dentin, good sealing abilities and it is well tolerated by immortalized odontoblast cells. It contains approximately $45 \%$ resin , $10 \% \mathrm{wt}$ radiopaque component, $5 \%$ wt hydrophilic thickening agent (fumed silica) [9]. The traditional technique used to prepare the root apex was usually performed with using a low-speed turbine and round bur. However, the application of piezo electric ultrasonic for root end preparations showed promising results in terms of optimal cleaning of apical tissue debris and minimally invasive technique with high efficiency. Piezoelectric device contains a crystal, when an electrical charge is applied; this crystal undergoes deformation that is converted into mechanical oscillation without producing heat [10]. Little information is available on the push out bond strength of retrograde filling material, so we tested the validity of the hypothesis that there is no difference in the filling quality of the tested retrograde filling materials. Therefore, this laboratory study was conducted to compare the bond strengths of Biodentine, TheraCal LC, and white ProRoot using a push-out force methodology and to compare the effect of ultrasonic preparation of retrograde cavity with conventional rotary method on push-out bond strength of the three bioactive materials.

\section{Materials and methods}

\section{Teeth selection}

Thirty sound human single rooted teeth with mature apices were selected for this study (fig. 1), and then teeth were stored in distilled water at room temperature.
The teeth were sectioned horizontally close to the cementoenamel junction with a diamond disc under constant water cooling to obtain $16-\mathrm{mm}$ long $\operatorname{root}^{[8]}$.

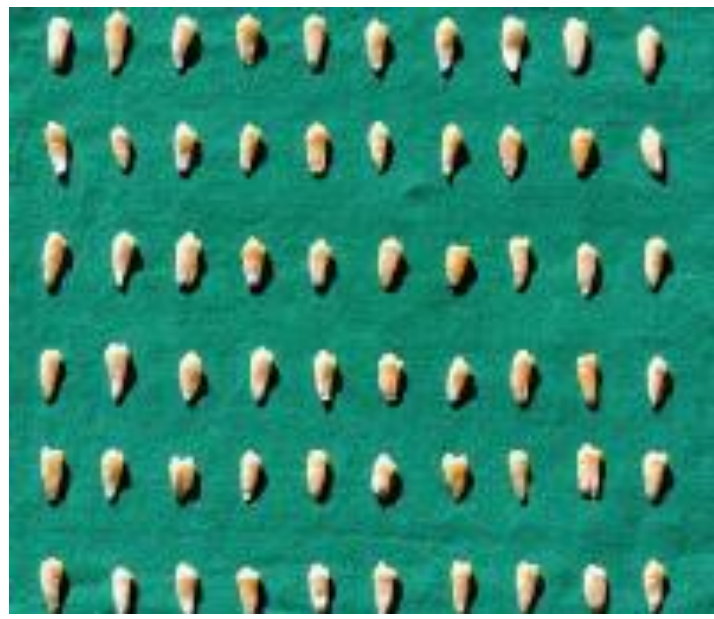

Figure 1: The selected teeth

\section{Preparation of specimens for push-out bond strength test}

Access cavities were prepared using no. 4 round bur, the root canal patency were confirmed by passing a $10-\mathrm{K}$ file, working length were determined. The canals were prepared with crown down technique using ProTaper system (SX to F5). A total of $10 \mathrm{ml}$ of $2.5 \%$ of sodium hypochlorite $(\mathrm{NaOCl})$ were used for irrigation during instrumentation then followed by irrigation with $5 \mathrm{ml}$ EDTA $17 \%$. The roots were dried with paper point after instrumentation, and then canals were obturated with gutta percha by lateral compaction technique [11). After biomechanical preparation and obturation of canals, the roots were sectioned transversally at two points: $3 \mathrm{~mm}$ short of the apical foramen with straight fissure bur perpendicular to the long axis of the root (which is the level of apicoectomy) and 4 $\mathrm{mm}$ coronally to this point to obtain an apical root section or slice of (4 $\mathrm{mm}$ high) [2].

\section{Sample Grouping:}

A total of 30 apical root slices of (4 $\mathrm{mm}$ high) were divided into three main groups (10 specimens) according to the type of retrograde filling and then each group were further subdivided into two main subgroups according to method of root end cavity preparation either with bur or ultrasonic tip.

Group A (Biodentine group) $(\mathrm{n}=10)$ : which were subdivided into:

A1 ( $\mathrm{n}=5)$ : in which a class I retro cavity at root end were prepared using Piezoelectric ultrasonic device (ESACROM, Italy) (fig. 2) equipped with diamond coated stainless steel ultrasonic surgical retro tip (surgysonic I, ES03A) (fig. 3) at $(30-\mathrm{kHz})$ frequency and $\mathbf{A} \mathbf{2}(\mathrm{n}=5)$ : In which class I retro cavity at root end were prepared with right-angled low speed Handpiece (W\&H, Austria) equipped with carbide round bur \#2 (Komet Dental, Austria). After that retrograde cavities were filled with Biodentine (Septodent, France) according to their manufacturers' instructions. 


\section{International Journal of Science and Research (IJSR) \\ ISSN (Online): 2319-7064}

Index Copernicus Value (2015): 78.96 | Impact Factor (2015): 6.391

Group B (MTA group) $(\mathrm{n}=10)$ : which were subdivided into:

B1 $(n=5)$ : in which a class I retro cavity at root end were prepared using Piezoelectric ultrasonic device (ESACROM, Italy) (fig. 2) equipped with diamond coated stainless steel ultrasonic surgical retro tip (surgysonic I, ES03A) (fig. 3) at $(30-\mathrm{kHz})$ frequency and $\mathbf{B 2}(\mathrm{n}=5)$ : In which class I retro cavity at root end were prepared with right-angled low speed Handpiece (W\&H, Austria) equipped with carbide round bur \#2 (Komet Dental, Austria). After that retrograde cavities were filled with MTA (ProRoot MTA, Dentsply) according to their manufacturers' instructions.

Group C (TheraCal LC group) $(n=10)$ : which were subdivided into:

C1 $(n=5)$ : in which a class I retro cavity at root end were prepared using Piezoelectric ultrasonic device (ESACROM, Italy) (fig. 2) equipped with diamond coated stainless steel ultrasonic surgical retro tip (surgysonic I, ES03A) (fig. 3) at (30-kHz) frequency and $\mathbf{C 2}(\mathrm{n}=5)$ : In which class I retro cavity at root end were prepared with right-angled low speed Handpiece (W\&H, Austria) equipped with carbide round bur \#2 (Komet Dental, Austria). After that retrograde cavities were filled with TheraCal LC (Bisco, Inc.) according to their manufacturers' instructions.

All the specimens were kept in wet gauze soaked with normal saline for 2 days at $37^{\circ} \mathrm{C}$ in an incubator until pushout test was applied. [11].

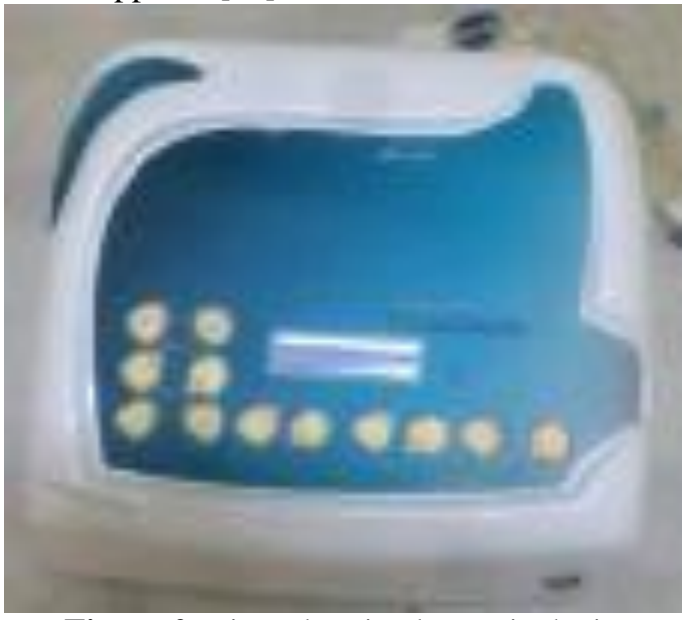

Figure 2: Piezoelectric ultrasonic device

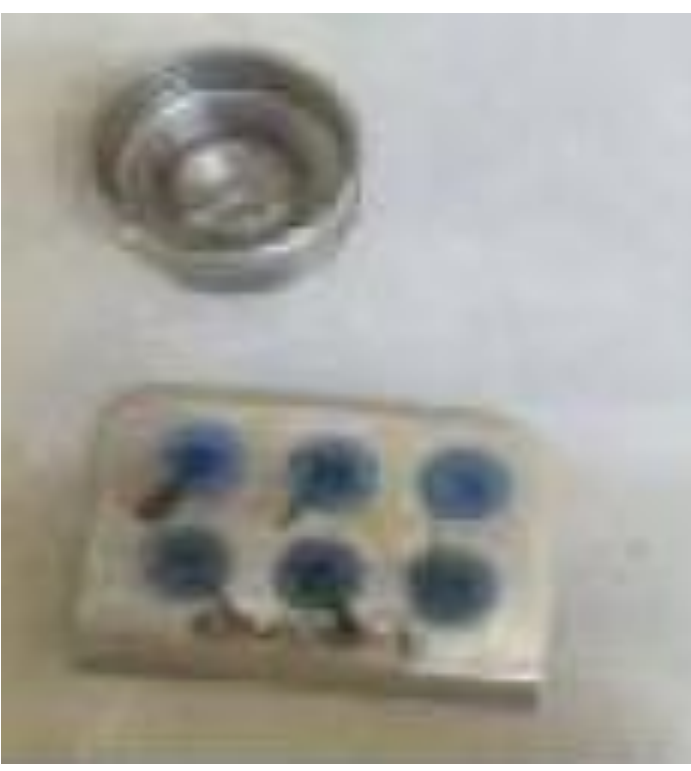

Figure 3: Ultrasonic surgical retro tips

\section{Push-out bond strength test}

The specimens were then fixed in an Instron universal testing machine (Instron Corp., Canton, MA, USA) (fig. 4) in such a way that the root-end filling faced downwards and were aligned to the shaft. The samples were placed on a metal slab with a central hole to allow free motion of the plunger (fig. 5). Compressive load were applied by exerting downward pressure on the surface of materials with a load cell of $5 \mathrm{kN}$ at a crosshead speed of $0.5 \mathrm{~mm} / \mathrm{min}$ using 1 $\mathrm{mm}$ diameter cylindrical jig at a speed of $1 \mathrm{~mm} / \mathrm{min}$. The jig has a clearance of approximately $0.2 \mathrm{~mm}$ from the margin of dentinal wall to insure contact with material only. Maximum load applied to material at the time of dislodgement were recorded in Newton's and data were recorded using computer software [1].

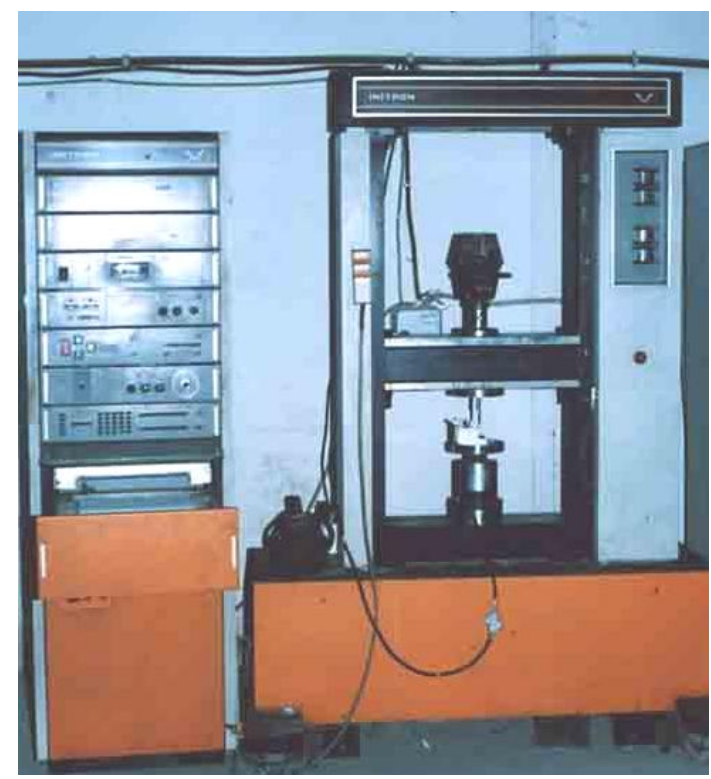

Figure 4: Instron testing machine 


\section{International Journal of Science and Research (IJSR) \\ ISSN (Online): 2319-7064}

Index Copernicus Value (2015): 78.96 | Impact Factor (2015): 6.391

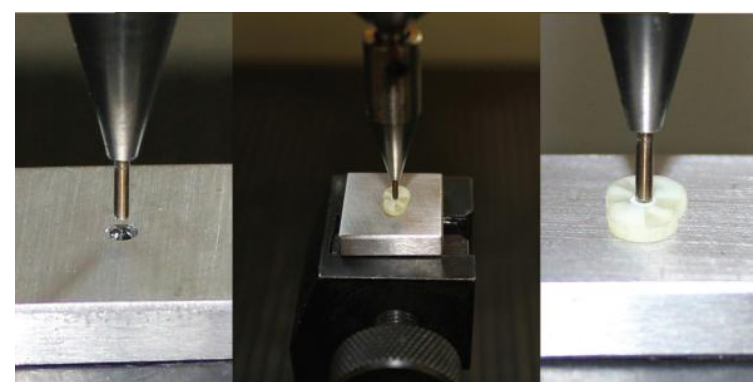

Figure 5: (Push-out test design)

The bond strength was calculated from the recorded peak load divided by the computed surface area that was obtained by the following formula:

\section{bond strength(MPa)=load (N) /adhesion area of filling $\left(\mathrm{mm}^{\wedge} \mathbf{2}\right)$}

The bonded (adhesion) area of each section was calculated as the follow:

$(\pi \mathrm{r} 1+\pi \mathrm{r} 2) * \mathrm{~L}$. (L) was calculated as the follow:

$\mathrm{L}=\sqrt{ }(\mathrm{r} 1-\mathrm{r} 2)^{\wedge} 2+\mathrm{h}^{\wedge} 2$

Where $\mathbf{r} \mathbf{2}$ the coronal radius, $\mathbf{r} \mathbf{1}$ the apical radius, $\boldsymbol{\pi}=3.14$ and $\mathbf{h}$ the thickness of the section.

Failure manifested by extrusion of filling material and confirmed by sudden drop along load-deflection curve recorded by computer software [7].

The slices were then examined under a light microscope at $20 \times$ magnification to determine the nature of the bond failure. Each sample were categorized into one of the three failure modes: adhesive, cohesive or mixed failure [3].

\section{Statistical analysis}

Mean and standard deviation were estimated from the samples for each study groups. Mean values were compared by one-way ANOVA / LSD test. SPSS statistical software version 18 (IBM. SPSS Inc.USA) were employed to analyze the tested groups.

\section{Results}

The mean, minimum, maximum, standard error and standard deviation of push out bond strength of three experimental groups were illustrated in (table 1) and (fig.6)

Table 1: Mean values of push-out bond strength of retrograde cavities in $(\mathrm{MPa})$

\begin{tabular}{|c|c|c|c|c|c|c|}
\hline Groups & $N$ & Mean & S.E. & S.D. & Min. & Max. \\
\hline A1 & 5 & 8.74 & 0.16 & 0.36 & 8.3 & 9.2 \\
\hline B1 & 5 & 6.8 & 0.26 & 0.59 & 6 & 7.5 \\
\hline C1 & 5 & 3.7 & 0.18 & 0.57 & 3.2 & 4.2 \\
\hline A2 & 5 & 7.64 & 0.22 & 0.69 & 7 & 8.1 \\
\hline B2 & 5 & 6.16 & 0.19 & 0.61 & 5.5 & 6.8 \\
\hline C2 & 5 & 3.14 & 0.27 & 0.61 & 2.5 & 4 \\
\hline
\end{tabular}

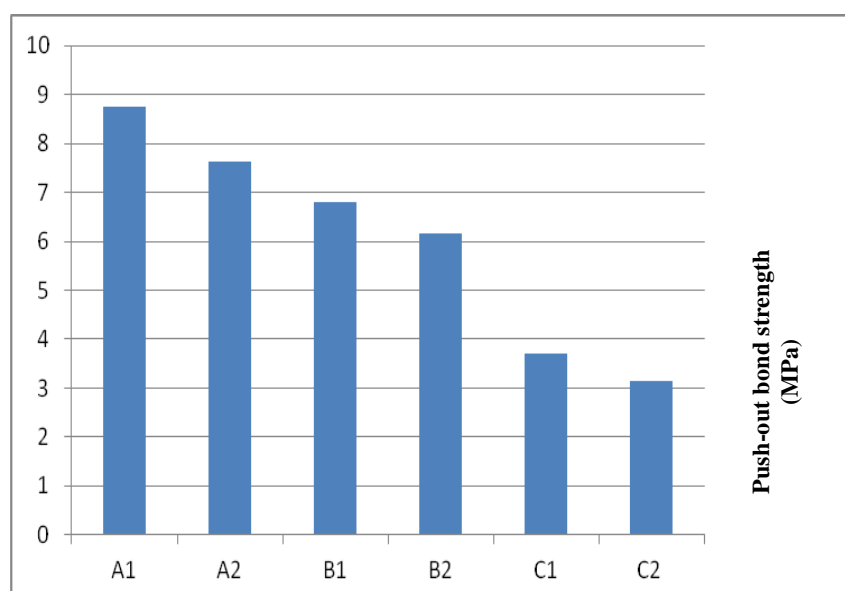

Figure 6: Mean values of push out bond strength in (MPa) of the tested groups

The overall comparison of push out bond strength at the dentin- retrograde filling material inter-face has shown that bond strength was maximum for Biodentin group followed by MTA and then Theracal for both techniques of retrograde cavity preparation

Ultrasonically-prepared cavities had more bond strength than micro prepared cavities, so push out bond strength was highest with apical cavities prepared ultrasonically group A1 (Biodentine group) $(8.74 \pm 0.16)$ followed by microprepared cavities group A2 (Biodentine group) $(7.64 \pm 0.22)$ and it was lowest with ultrasonically-prepared cavities Group C1 (TheraCal LC group) (3.7 \pm 0.18 ) followed by microprepared cavities Group C2 (TheraCal LC group) (3.14 \pm 0.27$)$ So, on the basis of table (1) and the diagram fig (6), we can conclude the following results: $\mathrm{A}>\mathrm{B}>\mathrm{C}$

In order to identify the presence of statistical significant difference between groups according to the type of retrograde filling material, ANOVA test was carried on.

Table 2: One-way ANOVA test to show the statistical difference of push-out bond strength between ultrasonic groups with different retrograde fillings

\begin{tabular}{|c|c|c|c|c|c|c|}
\hline ANOVA & $\begin{array}{c}\text { Sum of } \\
\text { Squares }\end{array}$ & d.f & $\begin{array}{c}\text { Mean } \\
\text { Square }\end{array}$ & F-test & $\begin{array}{c}p- \\
\text { value }\end{array}$ & $\begin{array}{c}\text { Sig } \\
.\end{array}$ \\
\hline Between Groups & 39.609 & 2 & 8.494 & \multirow{2}{*}{102.262} & 0.000 & HS \\
\hline Within Groups & 2.324 & 12 & \multirow{2}{*}{.074} & & & \\
\hline Total & 41.933 & 14 & &
\end{tabular}

Table 3: One-way ANOVA test to show the statistical difference of push-out bond strength between microprepared groups with different retrograde fillings

\begin{tabular}{|c|c|c|c|c|c|c|}
\hline ANOVA & $\begin{array}{c}\text { Sum of } \\
\text { Squares }\end{array}$ & d.f. & $\begin{array}{c}\text { Mean } \\
\text { Square }\end{array}$ & F-test & p-value & Sig. \\
\hline Between Groups & 80.865 & 2 & 40.433 & & & \\
\cline { 1 - 3 } Within Groups & 3.404 & 12 & .284 & 142.536 & .000 & HS \\
\hline Total & 84.269 & 14 & .284 & & \\
\hline
\end{tabular}

The ANOVA results had shown highly significant influence ( $P<0.001)$ of type of retrograde filling material, the statistical analysis of data revealed that push out bond strength of ultrasonic subgroups was highly significant (A1 Biodentine, B1 MTA and C1 TheraCal ) P<0.001 (table 2). Also there was a highly significant difference when 


\section{International Journal of Science and Research (IJSR) \\ ISSN (Online): 2319-7064}

Index Copernicus Value (2015): 78.96 | Impact Factor (2015): 6.391

comparing manual prepared subgroups (A2 Biodentine , B2 MTA and C2 TheraCal ) $\mathrm{P}<0.001$ (table 3).

When a significant difference was found, least significant difference (LSD) test was done to analyze the data to show the difference in push out bond strength between different subgroups according to type of retrograde cavity preparation , table (4)

Table 4: The least significant difference (LSD) of multiple comparison tests for studied subgroups according to type of retrograde cavity praparation

\begin{tabular}{|c|c|c|c|}
\hline A1 & A2 & 0.002 & S \\
\hline B1 & B2 & 0.99 & NS \\
\hline C1 & C2 & 0.125 & NS \\
\hline
\end{tabular}

These investigations had shown that there was a significant difference $(\mathrm{P}<0.05)$ between Biodentin subgroups according to the type of retrograde cavity preparation, while there was non significant difference (P>0.05) between B (MTA) and C (TheraCal) subgroups when method of cavity preparation was compared.

We observed the bond failures in large number of MTA groups predominantly adhesive type. TheraCal showed predominance of mixed failures. Almost all Biodentine samples revealed a cohesive bond failure.

\section{Discussion}

Good clinical prognosis is the outmost goal for any endodontic treatment, so the selection of appropriate retrograde filling material that has adequate physicochemical properties and fulfills the criteria of biocompatibility, cytotoxicity, apical seal and marginal adaptation is critical for insuring favorable outcome of endodontic surgery [12]. Among the physicochemical properties, adhesiveness to intraradicular dentin is of particular interest because root-end filling materials must be able to remain adapted to the dentin walls when the teeth are subjected to mechanical forces occurring during function or operative and surgical procedures[2].

The push-out bond strength test was used, as it is the most reliable method for evaluating the resistance of materials to dislodgement forces, based on the results of previous studies [13].

Under certain clinical applications calcium silicate-based materials are used for the repair of root and furcation perforations, root-end fillings, and apical plugs [14]. The bioavailability of calcium $(\mathrm{Ca})$ ions inside these materials stimulate the expression of bone-associated proteins mediated by calcium channels and large quantities of $\mathrm{Ca}$ ions could activate ATP, which plays a significant role in the mineralization process [15]. Across conditions, Biodentine, MTA and TheraCal demonstrated highly statistical difference in push-out strengths, $(\mathrm{P}<0.001)$. In this study Biodentine showed the highest bond strength among groups. These results are in accordance with those of Vivek et al [13] who found significant difference between bond strength of tested groups revealing that MTA had the lowest bond strength and attributed this to the prolonged maturation process of MTA because of the formation of passivating trisulfate layer over hydrating crystals that simulates a bad clinical situation. Our results disagree with Rahimi et al [16] who reported no significant differences in the bond strength of Biodentine and MTA.

Han and Okiji et al [17] showed that calcium and silicon ion uptake into dentin, leading to the formation of tag-like structures alongside an interfacial layer called the "mineral infiltration zone," in Biodentine, which was higher than in MTA, also Biodentine has a similar composition to MTA, differing mostly by being aluminium-free and having tantalum oxide as a radi-opacifier in place of the bismuth oxide in MTA. These two properties may be the reason of improved biological properties of Biodentine [18].

Theracal is pulp-capping material but due to its good sealing ability we used it as root end filling material. It showed lower bond strength than MTA and Biodentin. This result disagrees with Sameer et al [5] who found better performance of TheraCal when compared to Biodentin and MTA. The low dislodgment force of Theracal obtained in our study could be explained by its heterogeneous structure that leads to formation of large unhydrated particles affecting $\mathrm{Ca}$ ion release and compromising mineralization process and subsequent bond [19]. Further in vivo and in vitro research should be done in order to assess Theracal as root end filling material.

The development of ultrasonic retrotips has changed the root end therapy. Piezoelectric device contains a crystal, when an electrical charge is applied; this crystal undergoes deformation that is converted into mechanical oscillation without producing heat [20]. Ultrasonic device has improved the surgical procedures because it provided better access to the root end cavity, Furthermore, the geometry of the retrotip does not produce beveled cavity outline, so this will decrease the exposed dentinal tubules and minimizes apical leakage and decreasing amount of debris to allow for more intimate contact of the material to the cavity walls and better bond strength [10]. This could explain our results in which we found push out bond of ultrasonic prepared cavities were significantly higher than micro prepared cavities.

All samples were condensed with a hand condenser and hand pressure due to the effectiveness of this method to prevent the formation of more voids [7].

In the present study, all the samples were kept in wet gauze in normal saline for two days, before the push-out assessment. The moistening of calcium silicate cements during setting is particularly important, since these cements have greater comprehensive strength when kept in a moist environment. In addition, the retention characteristic and push-out strength of calcium silicate cements increases over time if kept under moist conditions [21].

We observed the bond failures in large number of MTA groups predominantly (adhesive type), agreeing with Shokouhinejad et al [22] and Vanderweele et al [23], but disagrees with Noushin et al [18] who revealed that most

\section{Volume 6 Issue 7, July 2017 www.ijsr.net}




\section{International Journal of Science and Research (IJSR) \\ ISSN (Online): 2319-7064}

Index Copernicus Value (2015): 78.96 | Impact Factor (2015): 6.391

MTA bond failures were mixture of cohesive and adhesive. Those authors associated this failure mode to the material displacement caused by its high compressive strength. However, TheraCal showed predominance of mixed failures. This failure mode could be related to the low compressive strength of TheraCal compared to Biodentine and MTA. The adhesive mode of failure may be caused also by the short storage time before the evaluation of the bond strength, which was 2 days. In contrast, almost all Biodentine samples revealed a cohesive bond failure. The particle size could explain the difference of failure mode between MTA and Biodentine which affects the penetration of cement into dentinal tubules. A smaller particle size and uniform components might have a role in better interlocking of Biodentine with the dentin, which finally causes cohesive failure [19].

\section{Conclusions}

Under the conditions of this in vitro study, it can be concluded that:

1) The force needed for the dislodgement of Biodentine from root dentin was statistically highly significant when compared to MTA and TheraCal. From a clinical point of view, the present results are favorable for Biodentine.

2) Statistically significant differences were found comparing the results of ultrasonic retrotip preparation versus conventional bur preparation for Biodentin group in which ultrasonics produced significantly better pushout bond strength than conventional bur preparation, while there was no significant difference for MTA and Thera Cal groups between ultrasonic and conventional method.

\section{References}

[1] Pablo A, AMOROSO S, Marina A, Bruno M. Apical adaptation, sealing ability and push-out bond strength of five root-end filling materials. Braz Oral Res. 2014; 28(1).

[2] Jorge H, Yara T, Fuad J, Jardel F. New methodology to evaluate bond strength of root-end filling materials. Brazilian Dental Journal. 2015; 26(3):288-291.

[3] Fereshte S, Safoora S, Misagh N. Effect of Acidic Environment on the Push-Out Bond Strength of Calcium-Enriched Mixture Cement. IEJ. 2014; 9(4):266-270

[4] Eduardo D, Filho k, Felipe C, Push-out bond strength of a self-adhesive resin cement used as endodontic sealer. The Korean Academy of Conservative Dentistry. 2014; 1-6.

[5] Sameer M, Ruchi V, Anita K. The Effect of altered pH on push-out bond strength of Biodentin, Glass Ionomer Cement, Mineral Trioxide Aggregate and Theracal. Serbian Dental Journal. 2015; 62(1).

[6] Snehal S, Rucheet P. Bioactive materials in conservative dentistry. International Journal of Contemporary Dental and Medical Reviews. 2015; 41(2).

[7] Mohammad A, Armen, AmFranklin G. The impact of thermocycling process on the dislodgement force of different endodontic cements. Hindawi Publishing
Corporation BioMed Research International. 2013; 55(6).

[8] Bernice T, Manoj C, Aditya P. Effect of $\mathrm{pH}$ on the compressive strength of Grey Mineral Trioxide Aggregate and Biodentine. Journal of Dental and Medical Sciences. 2014; 10 (50-53).

[9] - Claudio P, Carla R, Riccardo B. Cytocompatibility and Antibacterial Properties of Capping Materials. Scientific World Journal. 2014; 10 (9).

[10] Gianluca P, Cornelis H, Pameijer, Nicola M, Francesco S. Ultrasonics in endodontics: A review of the literature. JOE. 2007; 33(2):81-93.

[11] Huseyin E, Ebru K, Evren O. Push-out bond strength of different mineral trioxide aggregates. European Journal of Dentistry. 2014; 8(3).

[12] Saghiri M, Shokouhinejad N, Lotfi M, Saghiri A. Push-out bond strength of mineral trioxide aggregate in the presence of alkaline pH. J Endod 2010; 36:18561859.

[13] Vivek A, Mamta S, Sanjay M, Sarita K. Comparative evaluation of push-out bond strength of ProRoot MTA, Biodentine, and MTA Plus in furcation perforation repair. Journal of Conservative Dentisry. 2013; 16(5).

[14] Alireza A, Fereshte S, Nooshin S, Niloofar A. Effect of blood contamination on the push-out bond strength of two endodontic biomaterials. 2016; 9(18).

[15] Emmanuel J, Nancy K, Mayara Z. Push-out bond strength of MTA HP, a new high-plasticity calcium silicate-based cement. Braz. Oral Res. 2016; 30(1).

[16] Rahimi S, Ghasemi N, Shahi S, Lotfi M, Froughreyhani M, Milani A. effect of blood contamination on the retention characteristics of two endodontic biomaterials in simulated furcation perforations. J Endod. 2013; 39(5).

[17] Han L, Okiji T. Uptake of calcium and silicon released from calcium silicate-based endodontic materials into root canal dentine. Int Endod J 2011; 44:1081-7.

[18] Noushin S, Hasan R, Mohammad S. Push-out bond strength of Bioceramic materials in synthetic fluid. Journal of dentistry. 2013; 10(6).

[19] Maria G, Fransisco S, Carlo P. Chemical-physical properties of TheraCal, a novel light-curable MTA-like material for pulp capping. International Endodontic Journal. 2012; 45(8).

[20] Ravi P, Harikumar V, Deepthi K, JayaPrada R, RamKiran D, Jaya N, Krishna M, Gita m. Comparative evaluation of marginal adaptation of BiodentineTM and other commonly used root end filling materials-an in vitro study. J Clinical and Diagnostic Res 2014; 8(3): $243-5$

[21] Aminoshariae A, Hartwell GR, Moon PC. Placement of mineral trioxide aggregate using two different techniques. J Endod. 2003;29:679-82.

[22] Shokouhinejad N, Nekoofar M, Iravani A, Kharrazifard M, Dummer P. Effect of acidic environment on the push-out bond strength of mineral trioxide aggregate. J En-dod. 2010; 36(5).

[23] Vanderweele R, Schwartz S, Beeson T. Effect of blood contamination on retention characteristics of MTA when mixed with different liquids. J Endod. 2006 May; 32(5). 